\title{
Urethro-vesical dysfunction in progressive autonomic failure with multiple system atrophy
}

\author{
ROGER KIRBY,* CLARE FOWLER,* JOHN GOSLIING, $\dagger$ ROGER BANNISTER \\ From the Department of Urology, Middlesex Hospital,* London, The National Hospital for Nervous Diseases, $\ddagger$ \\ London, and the Department of Anatomy, University of Manchester, $\dagger U K$
}

SUMMARY Fourteen patients with progressive autonomic failure and multiple system atrophy have been investigated by urodynamic, electromyographic and neurohistochemical means and the results compared with a series of age-matched controls. Three fundamental abnormalities of lower urinary tract function have been identified: (1) Involuntary detrusor contractions in response to bladder filling. It is suggested that these may be the result of a loss of inhibitory influences from the corpus striatum and substantia nigra. (2) Loss of the ability to initiate a voluntary micturition reflex. This may reflect the degeneration of neurons in pontine and medullary nuclei and in the sacral intermediolateral columns. In addition, these studies have demonstrated a significant reduction in the density of acetylcholinesterase-containing nerves in bladder muscle. (3) Profound urethral dysfunction. This appears to be partly due to a loss of proximal urethral sphincter tone, which causes bladder neck incompetence. In addition, the function of the striated component of the urethral sphincter is impaired. Individual motor units recorded from this muscle were clearly abnormal when compared with controls and suggested that reinnervation had occurred. We suggest that this is the result of degeneration of a specific group of sacral anterior horn cells known as Onuf's nucleus. The evidence that these particular motor units are affected, while others are spared, poses fundamental questions about the nature of selective vulnerability in degenerative diseases of the nervous system.

A condition characterised by autonomic dysfunction was described by Bradbury and Eggleston in $1925^{1}$ as "idiopathic orthostatic hypotension". In 1960 Shy and Drager ${ }^{2}$ reported two cases in which autonomic failure was accompanied by more widespread neurological involvement; they were the first to suggest that this might represent a distinct degenerative disorder of the nervous system. It is now recognised that when autonomic failure due to other diseases such as diabetes, alcoholism and amyloidosis is excluded, there is a residuum of primary degenerative disorders in which progressive autonomic failure may occur. Progressive autonomic failure may be found in isolation, in combination with Parkinson's disease, or, as Shy and Drager described, in association with more complex neurological degeneration which constitutes

Address for reprint requests: Sir Roger Bannister, The National Hospital for Nervous Diseases, Queen Square, London, WCIN 3BG, UK

Received 3 May 1985 and in revised form 1 July 1985. Accepted 6 July 1985 multiple system atrophy. ${ }^{3}$ While all these variants are rare, progressive autonomic failure with multiple system atrophy is the most frequently encountered, and forms the basis of this study.

Although the underlying cause for the degeneration of autonomic neurons is unknown, the sites that are selectively affected have been defined. ${ }^{4}$ Vulnerable structures include the corpus striatum, the substantia nigra, the pontine, olivary and dorsal vagal nuclei, the Purkinje cells of the cerebellum and the cells of the intermediolateral column in the spinal cord. In addition, a specific group of cells in the anterior horn of the sacral spinal cord, known as Onuf's nucleus, ${ }^{5}$ appears to be affected. There is some debate as to whether this loss of central autonomic neurons is accompanied by a loss of post-ganglionic sympathetic and parasympathetic nerves. The remarkable specificity of the lesions in these cases endows their investigation with a special interest since, from the study of the nature of this disorder, much may be deduced about the mechanisms of autonomic control in both disease and health.

While much attention has been paid to the cardio- 
vascular consequences of progressive autonomic failure with multiple system atrophy, relatively few data are available concerning the disturbances of urinary continence and micturition that invariably accompany this disease. We present here the results of a detailed urodynamic, electromyographic and neurohistochemical study of the urethro-vesical dysfunction in 14 patients with progressive autonomic failure and multiple system atrophy. An attempt is made to correlate these findings with the localised neuro-pathological lesions known to occur in this disorder.

\section{Patients}

Fourteen patients (11 male and three female) were admitted for study. Their mean age was 56 years (range 43-67). All had significant orthostatic hypotension and a diagnosis of progressive autonomic failure with multiple system atrophy, based on the clinical features of autonomic failure, Parkinsonism and pyramidal signs and confirmed by physiological studies as described by Bannister ${ }^{3}$ (table). None of the patients had Parkinson's disease with autonomic failure. Two of the patients (TR and KP) had, in addition to signs of multiple system atrophy, cerebellar signs pointing to the additional feature of olivo-ponto-cerebellar atrophy, a recognised associated feature of multiple system atrophy. ${ }^{3}$ A group of 10 controls were also studied (mean age 53 years); these were patients who had been admitted for renal or ureteric surgery and who complained of neither micturition disturbance nor incontinence. All patients provided written, informed consent.

\section{Methods}

A history was obtained from each patient and a physical and neurological examination performed. Blood urea levels were measured and an intravenous urogram carried out in every case. Urodynamic assessment was performed using mediumfill cystometry with simultaneous radiography as described by Bates. ${ }^{6}$ Simultaneous electromyography (EMG) was not performed because the low overall level of pelvic floor and sphincter activity made the use of surface electrodes impractical. Other authors ${ }^{78}$ have reported similar difficulties in obtaining synchronous EMG and urodynamic recordings in patients with progressive autonomic failure and multiple system atrophy. Instead EMG recordings from the striated muscle of the urethral sphincter ${ }^{9}$ were made in male patients with the subject in the left lateral position with flexed knees. Women lay supine with hips flexed and abducted. A concentric needle electrode (Disa, $30 \mathrm{~mm}$ in length, $0.45 \mathrm{~mm}$ tip diameter) was used. In male subjects the needle was inserted through the perineum in the midline and the tip guided to the level of the apex of the prostate by a finger in the rectum; in female patients the electrode was inserted at a point $1 \mathrm{~cm}$ lateral to the urethral meatus and guided towards the midline. Positioning of the needle tip was aided by listening to the audio output from the electrophysiological recording unit (Medelec MS6). Individual motor units were identified using a delay line and signal triggering; they were recorded on light-sensitive paper, either by repeated superimposition, or as a "falling leaf" display. A mean of seven spontaneously firing motor units were analysed from each patient; the small size of the muscle, particularly in females, limited the number of needle position changes that could be made. The consistency of waveform seen on examining a motor unit confirmed that the potentials were produced by a single motor unit. The duration and amplitude of individual units were measured from photographic records; the number of phase reversals of voltage of more than 100 microvolts were determined, and a unit was considered to be polyphasic if more than five phase reversals occurred.

Bladder muscle samples were taken during cystoscopy using Storz biopsy forceps. Tissue was taken from an area $2 \mathrm{~cm}$ lateral to the ureteric orifices on each side, and from the trigonal region, then rapidly frozen in liquid nitrogen slush

Table Details of patients with progressive autonomic failure and multisystem atrophy

\begin{tabular}{|c|c|c|c|c|c|c|c|}
\hline \multirow[t]{2}{*}{ Patient } & \multirow[t]{2}{*}{ Sex } & \multirow[t]{2}{*}{ Age (Ir } & \multirow[t]{2}{*}{ Diagnosis } & \multirow{2}{*}{$\begin{array}{l}\text { Duration of disease } \\
(y r)\end{array}$} & \multicolumn{2}{|c|}{ Blood pressure } & \multirow[t]{2}{*}{ Comments } \\
\hline & & & & & Supine & Erect & \\
\hline MM & $\mathbf{M}$ & 47 & $\mathrm{PAF}+\mathrm{MSA}$ & 4 & $130 / 90$ & $110 / 70$ & Laryngeal involvement \\
\hline DW & $\mathbf{M}$ & 60 & $\mathrm{PAF}+\mathrm{MSA}$ & 10 & $130 / 90$ & $110 / 60$ & Severe incontinence \\
\hline BR & $\mathbf{M}$ & 55 & $\mathrm{PAF}+\mathrm{MSA}$ & 6 & $130 / 90$ & $110 / 70$ & Severe incontinence \\
\hline GS & $\mathrm{F}$ & 45 & PAF + MSA & 7 & $120 / 90$ & $110 / 50$ & Parkinsonian symptoms \\
\hline PP & M & 43 & PAF + MSA & 8 & $130 / 80$ & $80 / 60$ & Severe incontinence \\
\hline DJ & $\mathbf{M}$ & 63 & $\mathrm{PAF}+\mathrm{MSA}$ & 5 & $140 / 85$ & $80 / 60$ & Severe incontinence \\
\hline FF & $\mathbf{M}$ & 67 & $\mathrm{PAF}+\mathrm{MSA}$ & 7 & $140 / 85$ & $60 / 40$ & Severe incontinence \\
\hline DR & $\mathrm{F}$ & 65 & PAF + MSA & 6 & $110 / 70$ & $80 / 50$ & Severe incontinence \\
\hline $\mathrm{MS}$ & $\mathbf{M}$ & 50 & $\mathrm{PAF}+\mathrm{MSA}$ & 4 & $110 / 70$ & $80 / 55$ & Severe incontinence \\
\hline TR & $\mathbf{M}$ & 66 & $\begin{array}{l}\mathrm{PAF}+\mathrm{MSA} \\
(\text { also OPCA) }\end{array}$ & 5 & $130 / 80$ & 11060 & Laryngeal involvement \\
\hline KP & $\mathrm{F}$ & 57 & $\begin{array}{l}\mathrm{PAF}+\mathrm{MSA} \\
(\text { also OPCA })\end{array}$ & 3 & $100 / 60$ & $80 / 40$ & Bed-ridden; + incontinence \\
\hline LA & $\mathbf{M}$ & 54 & $\mathrm{PAF}+\mathrm{MSA}$ & 3 & $180 / 100$ & $120 / 80$ & Severe incontinence \\
\hline JW & $\mathbf{M}$ & 65 & $\mathrm{PAF}+\mathrm{MSA}$ & 4 & $150 / 90$ & $85 / 60$ & Severe incontinence \\
\hline RG & $\mathbf{M}$ & 65 & $\mathrm{PAF}+\mathrm{MSA}$ & 6 & $160 / 100$ & $90 / 50$ & Severe incontinence \\
\hline
\end{tabular}

PAF + MSA $=$ Progressive autonomic failure + multiple system atrophy.

OPCA + Olivo-ponto-cerebellar atrophy. 
and stored at $-70^{\circ} \mathrm{C}$. Specimens were subsequently processed for tissue cholinesterase ${ }^{10}$ and noradrenalinecontaining nerves. ${ }^{11}$ The density of acetylcholinesterasecontaining nerves in bladder muscle was assessed by a point-counting technique. An eye-piece graticule with a grid divided into $1 \mathrm{~mm}$ squares was used: at each point of intersection the nature of the underlying tissue (that is nerve or smooth muscle cell) was noted. Different areas of muscle were examined, far enough apart to preclude the possibility of counting any point twice. A minimum of 500 and a maximum of 2000 points were counted in each case, and a mean value for the density of innervation $/ \mathrm{mm}^{2}$ was calculated for each biopsy specimen and then for each patient. Statistical analyses were performed using non-parametric statistics (Mann-Whitney U-test) and the level of significance was taken as $1 \%$.

\section{Results}

In all the cases of progressive autonomic failure with multiple system atrophy in this series, frequency and urgency of micturition were amongst the presenting symptoms. In male patients, the only symptom that consistently preceded the onset of urinary difficulties was erectile impotence, often with failure of ejaculation. Every patient suffered urinary incontinence, by day and night. The urinary leakage was preceded by a feeling of urgency, but the patients were powerless either to prevent urine loss or to interrupt the stream once it had started. The patients were aware of, and far from indifferent to, their urinary incontinence, and most said that this was the most distressing and disabling feature of their disease.

The mean blood urea was $7 \cdot 1 \mathrm{mmol} / 1(\mathrm{SD} \pm 2 \cdot 1)$ and intravenous urography revealed evidence of moderate upper urinary tract dilatation in only one patient. In this case the ureters were thought to be partially obstructed where they passed through a hypertrophic bladder wall. The mean initial residual urinary volume was high at $215 \mathrm{ml}(\mathrm{SD} \pm 121)$. In control patients bladder filling proceeded without significant pressure rise (fig 1A). By contrast, in patients with progressive autonomic failure and multiple system atrophy, the cystometrogram revealed an intravesicular pressure rise of more than $20 \mathrm{~cm}$ of water in response to filling in every case (fig 1B) and this was usually associated with urinary incontinence which the patients seemed powerless to prevent. In the more advanced cases, while there was still a rise of intravesicular pressure, it was less pronounced than in the less severely affected patients (fig 1C). The mean subtracted intravesicular pressure rise was $49 \mathrm{~cm}$ of water $( \pm 22 \cdot 7)$. In every case the bladder neck was open during cystometry (fig 2) but sensation of bladder filling was normal.

When patients with progressive autonomic failure and multiple system atrophy were asked to micturate none was able to initiate or maintain detrusor con- traction. Voiding was achieved entirely by abdominal straining, which produced only an intermittent flow. The mean residual urinary volume was $233 \mathrm{ml}$ $( \pm 148)$.

In the control group urethral sphincter EMG revealed individual motor units that were usually of normal configuration (fig $3 \mathrm{~A}$ ) and $94 \%$ of units were shorter than $6 \mathrm{~ms}$ in duration and less than $2 \mu \mathrm{V}$ in amplitude (fig 3B). By contrast, in patients with progressive autonomic failure and multiple system atrophy, $56 \%$ of units were polyphasic (fig $4 \mathrm{~A}$ ), and $66 \%$ demonstrated measured parameters outside the control range (fig 4B). In no individual patient with progressive autonomic failure and multiple system atrophy were less than $40 \%$ of the recorded motor units abnormal, while in no individual control patient were more than $10 \%$ of the motor units abnormal.

Detrusor muscle biopsy specimens processed for tissue cholinesterases, demonstrated enzyme-positive autonomic nerve fibres in all patients (fig 5). Their arrangement and distribution in patients with progressive autonomic failure and multiple system atrophy was subjectively similar to that in controls. However, quantitative assessment of these nerves revealed a mean density of $232( \pm 58)$ nerves $/ \mathrm{mm}^{2}$ in patients with progressive autonomic failure and multiple system atrophy, compared with a density of $497( \pm 86)$ nerves $/ \mathrm{mm}^{2}$ in the control group (fig 6). This difference was statistically significant $(\mathrm{p}<0.01)$. Catecholamine-containing nerves, although exceedingly sparse, were present in specimens both from patients with progressive autonomic failure and multiple system atrophy and from controls.

\section{Discussion}

The disturbances of continence and micturition that are the main presenting feature of progressive autonomic failure with multiple system atrophy often progress to the extent that they become the patient's most distressing and disabling symptoms. The present study suggests that they are due to a combination of bladder and urethral dysfunction, which is the result of degeneration of specific autonomic and somatic neurons.

In each of our 14 patients with progressive autonomic failure and multiple system atrophy, the bladder failed to accommodate normally to filling by receptive relaxation. The neurophysiological mechanisms by which bladder accommodation normally occurs are incompletely understood. However, there is evidence in experimental animals that inhibitory influences from the midbrain are important ${ }^{12}$ and the areas involved in this inhibition have been identified as the globus pallidus ${ }^{13}$ as well as the pigmented nuclei, especially the substantia nigra. ${ }^{14}$ Significantly 


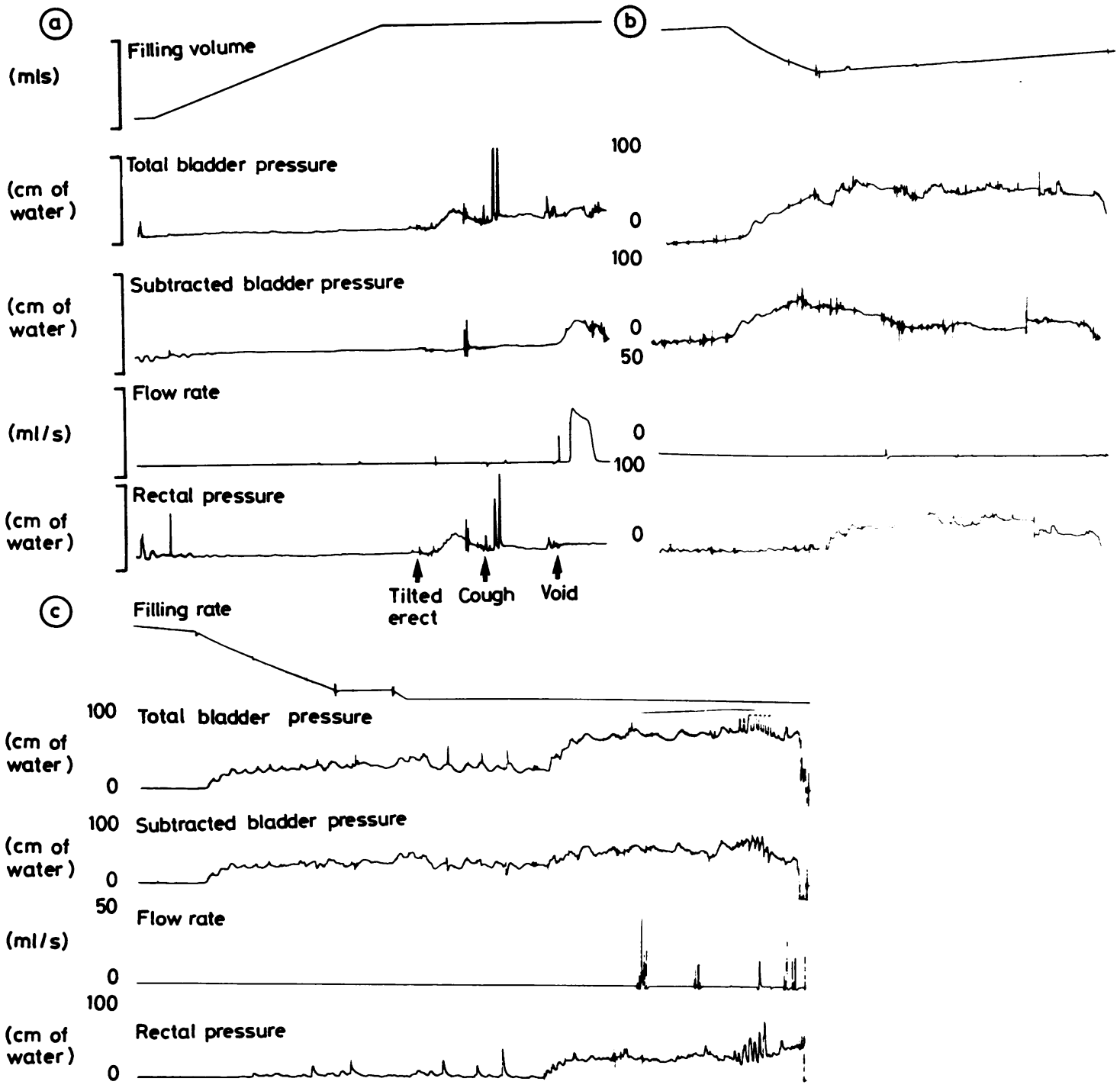

Fig 1 (a) A cystometrogram from a control subject demonstrating accommodation (that is the absence of intravesicular pressure rise) in response to bladder filling at a rate of $100 \mathrm{ml} / \mathrm{min}$. Normal micturition is achieved at a pressure of $25 \mathrm{~cm}$ of water and a maximum flow rate of $25 \mathrm{ml} / \mathrm{s}$. (b) Cystometrogram showing an abnormal intravesicular pressure rise with incontinence seen in response to bladder filling at a rate of $100 \mathrm{ml} / \mathrm{min}$ in a male patient with progressive autonomic failure and multiple system atrophy. There is a failure to initiate a micturition reflex and voiding is achieved entirely by abdominal straining. (c) Cystometrogram with bladder filling at a rate of $100 \mathrm{ml} / \mathrm{min}$ in a male patient suffering more advanced progressive autonomic failure and multiple system atrophy. Intravesicular pressure rise is less pronounced than that seen in patients less severely affected by the disease. The patient is unable to initiate a micturition reflex and voluntary voiding can only be achieved by abdominal straining.

it is precisely these loci that may be affected by neuronal degeneration in progressive autonomic failure with multiple system atrophy; all previous reported cases from which neuropathological data are available showed some degree of nigral damage, and many had cell loss from the corpus striatum. ${ }^{4}$ Neuronal degeneration in similar loci has been argued to account for the high incidence of detrusor hyperreflexia in Parkinson's disease. ${ }^{15} 16$

In four of the most severely affected patients in this 


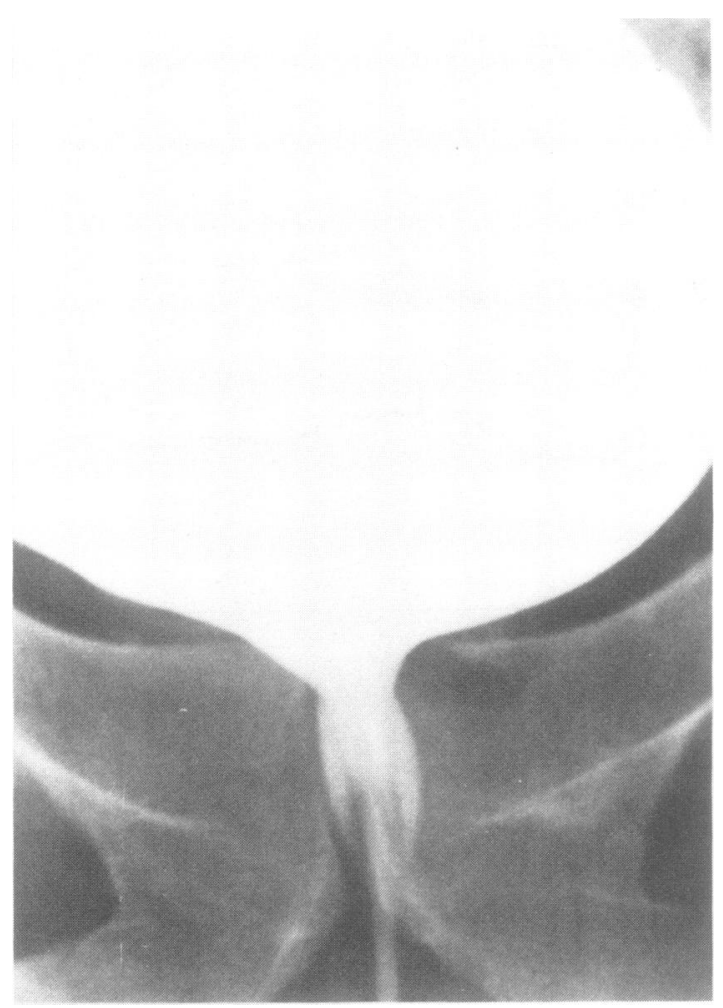

Fig 2 A cystogram showing the open bladder neck and dilated proximal urethra during bladder filling in a patient with progressive autonomic failure and multiple system atrophy.

series, the filling cystometrogram revealed a steep rise in intravesicular pressure with less pronounced phasic involuntary contractions (fig 2). Similar vesicourethral behaviour may be seen in the parasympathetically decentralised bladder after cauda equina lesions. ${ }^{17} \mathrm{~A}$ feature of all cases of progressive autonomic failure with multiple system atrophy, where neuropathological data are available, has been progressive cell loss from the thoraco-lumbar intermediolateral column. Sung et al $^{18}$ have shown that neurons of the sacral intermediolateral column may be similarly affected. There is now considerable evidence $^{19}$ that these cells in the sacral intermediolateral column are in fact preganglionic parasympathetic neurons. Progressive loss of these neurons would eventually interrupt the neural reflex arcs controlling continence and micturition and thus might be expected to produce a situation akin to the decentralised bladder seen in cauda equina injuries. Such a process could account for the differences of cystometric recordings between early and more advanced cases of progressive autonomic failure and (a)
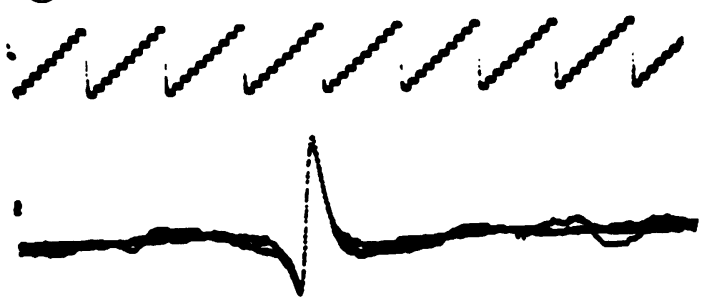

(b)

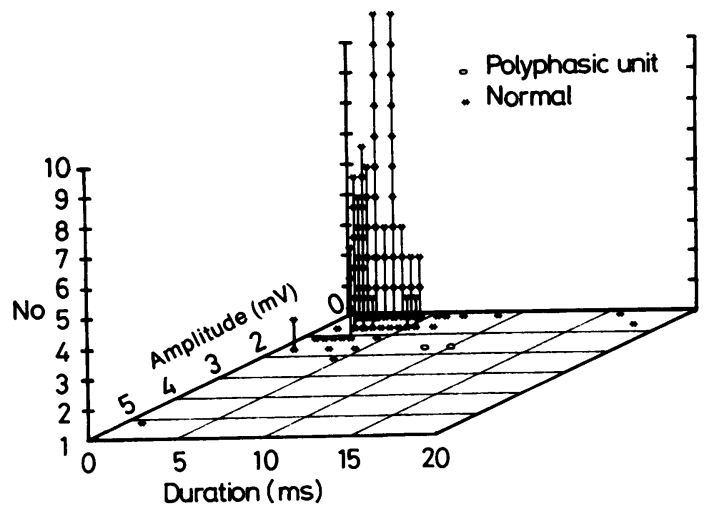

Fig 3 (a) A normal motor unit recorded from the striated urethral sphincter of a control subject.

(b) Three-dimensional histogram showing amplitude and duration of motor units recorded from control subjects.

multiple system atrophy.

A feature common to all 14 patients with progressive autonomic failure and multiple system atrophy in this study was a striking inability to initiate a voluntary micturition reflex; instead, voluntary voiding was achieved entirely by abdominal straining. Several studies have borne out Barrington's original suggestion ${ }^{20}$ that in the cat the normal micturition reflex is initiated and sustained by motor nuclei situated in the rostral pons ${ }^{21}$ and in the lateral. reticular formation of the medulla. ${ }^{22}$ Electrical stimulation of these neurons in experimental animals has been observed to produce firing of sacral preganglionic neurons and contractions of the bladder. $^{23}$ By contrast, electro-coagulation of the area results in permanent abolition of the micturition reflex. ${ }^{20}$ It is therefore significant that neuropathological studies in 41 patients with progressive autonomic failure and multiple system atrophy ${ }^{4}$ have revealed cell loss from pontine and dorsal vagal nuclei in 25 cases, in areas precisely equivalent to the detrusor motor nuclei in experimental animals.

There is controversy as to whether the loss of central autonomic neurons in progressive autonomic fail- 
(a) $1 / / / / / / / / / / / / / /$
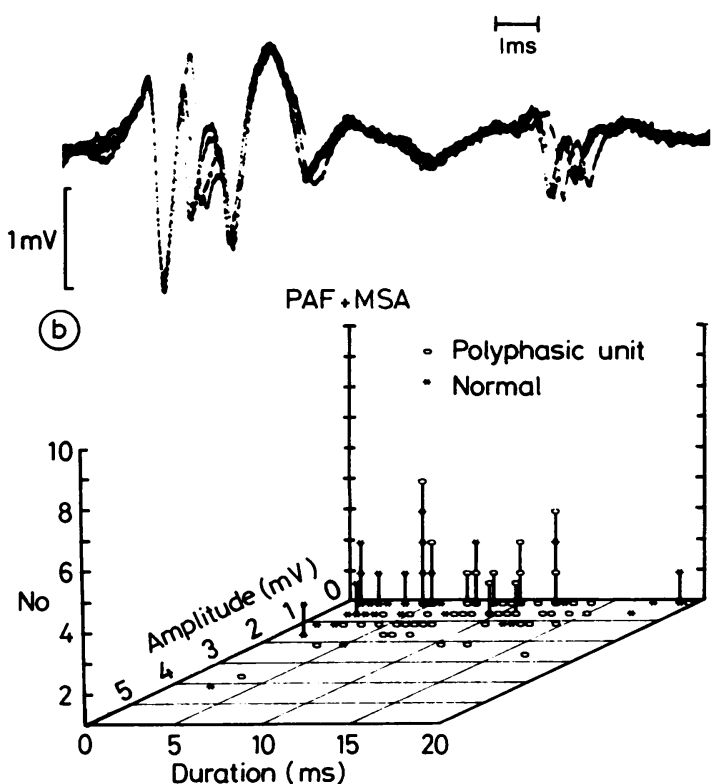

Fig 4 (a) A polyphasic motor unit of long duration recorded from the striated urethral sphincter of a patient with progressive autonomic failure and multiple system atrophy. (b) Three-dimensional histogram showing amplitude and duration of motor units recorded from patients with progressive autonomic failure and multiple system atrophy.

ure with multiple system atrophy is always accompanied by a depletion of peripheral autonomic nerves. It has been shown that plasma noradrenaline levels are low in many cases, and fail to rise when the patient is tilted. ${ }^{24}{ }^{25}$ However, such findings could be consistent either with loss of post-ganglionic sympathetic nerves or with decreased impulse traffic due to central neuronal loss. Nanda et $a l^{26}$ have reported normal adrenergic innervation of the blood vessels which supply skeletal muscle in some patients with neurogenic orthostatic hypotension, while Bannister et $a l^{27}$ on the other hand, have shown a reduction in both pure progressive autonomic failure, and progressive autonomic failure with multiple system atrophy. In the present study, the density of acetylcholinesterase-positive nerves in the bladder was quantitatively less than that in controls. This suggests that some parasympathetic nerve degeneration may occur in peripheral as well as central locations in these patients. Unfortunately, it was not possible to obtain similar data on peripheral sympathetic inner-

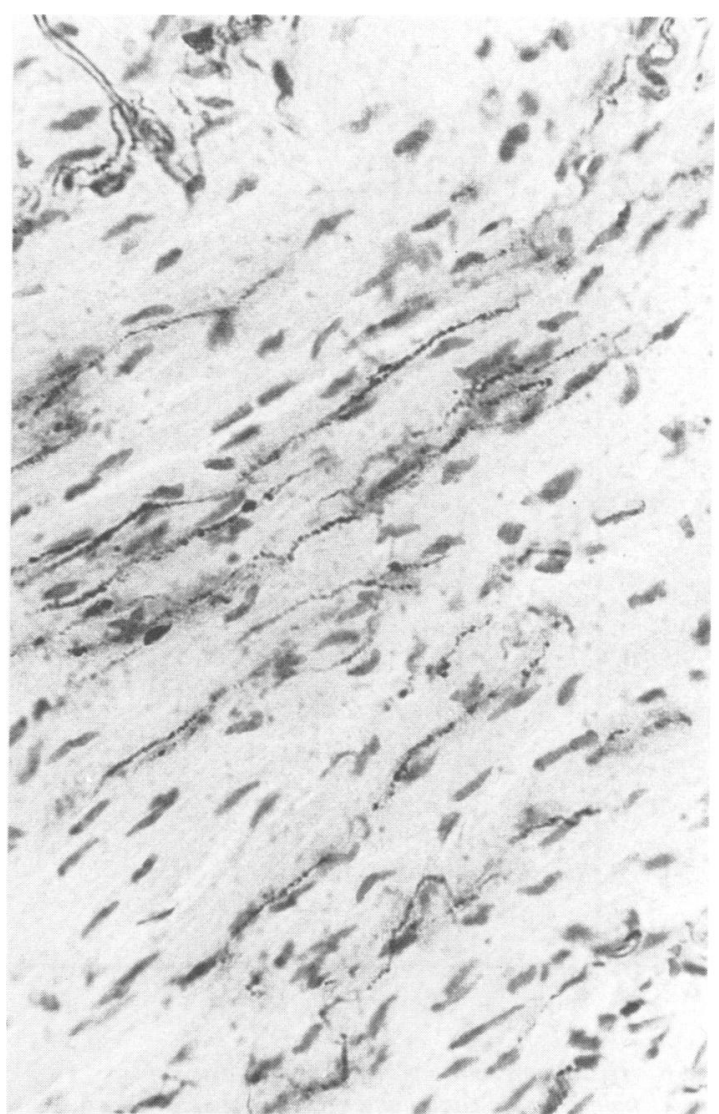

Fig 5 Bladder muscle biopsy specimen processed for tissue acetylcholinesterase from a patient with progressive autonomic failure and multiple system atrophy, showing the presence of darkly stained enzyme-containing nerves, lying among smooth muscle cells. (Magnification $\times 100$.)

vation in the urinary tract in these cases, because of the exceedingly sparse distribution of noradrenalinecontaining nerves in human detrusor muscle. ${ }^{28}$ Thus, insufficient numbers of nerves exhibiting catecholamine-fluorescence were seen in either control or progressive autonomic failure with multiple system atrophy groups to allow meaningful comparisons to be made between them.

Urethral sphincter EMG studies in our patients with progressive autonomic failure and multiple system atrophy showed that individual motor units, which appeared polyphasic and of long duration, were clearly abnormal when compared with controls. Sakuta et $a^{29}$ have reported similar findings in the external anal sphincter muscle of patients with this disorder. The presence of these abnormal motor units provides unequivocal evidence of reinnervation of striated sphincter muscle. The explanation for this 


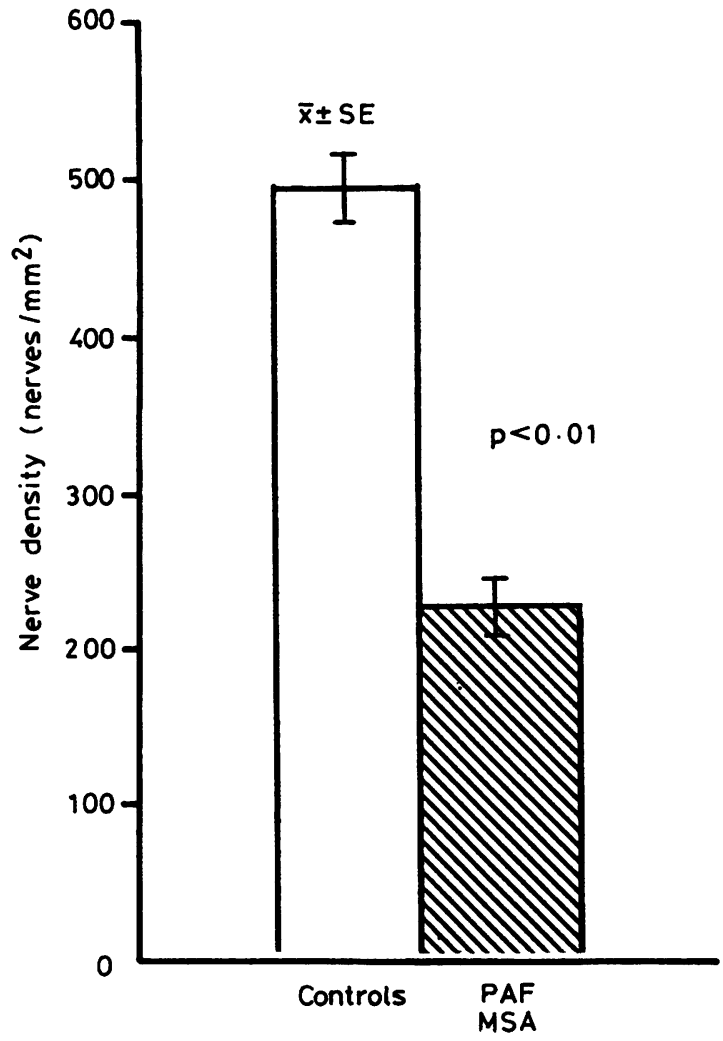

Fig 6 Histogram showing the reduced density of acetylcholinesterase-containing nerves of the bladder muscle of patients with progressive autonomic failure and multiple system atrophy compared with that of the control group.

may lie in the demonstration by Sung et $a l^{30}$ that patients with progressive autonomic failure and multiple system atrophy suffer specific neuronal degeneration of Onuf's nucleus, a particular area within the anterior horn of the sacral cord, which has been shown in experimental animals ${ }^{31}$ to be responsible for the innervation of the external anal and striated urethral sphincters. Degeneration of the motor neurons at this site would result in denervation of sphincter muscle fibres; and reinnervation could result from collateral sprouting of surviving motor nerves, as is seen in skeletal muscle in motor neuron disease. ${ }^{32}$ It is known that the striated urethral sphincter muscle plays a part in producing the rapid adjustments of urethral pressure necessary to prevent urinary leakage when intra-abdominal pressure rises, or unstable bladder contractions occur. Loss of the ability to achieve such adjustments, especially when associated with involuntary detrusor contractions and incompetence of the proximal urethra, may account for the severity of urinary incontinence in patients with progressive autonomic failure and multiple system atrophy.

While denervation affecting voluntary skeletal muscle may occur in progressive autonomic failure with multiple system atrophy, ${ }^{33}$ it is never a prominent feature. It is a matter for speculation why the motor neurons of the urethral and anal sphincters should be selectively vulnerable in this disease. In other degenerative disorders, such as motor neuron disease $^{34}$ and Werdnig-Hoffman disease ${ }^{3035}$ where there is severe generalised anterior horn cell loss, the cells of Onuf's nucleus have been shown to be spared. Clearly, these cells differ in some fundamental way from other motor neurons.

The striated muscle of the urethral and anal sphincters differs from other skeletal muscle in exhibiting tonic EMG activity, which persists even during sleep and general anaesthesia. The only structure that bears close comparison is the larynx, whose posterior cricoarytenoid muscle is constantly active in order to maintain abductor tone. Significantly, EMG studies of the cricoarytenoid muscles have revealed evidence of denervation in patients with progressive autonomic failure and multiple system atrophy, ${ }^{36}$ and histological examination has confirmed changes consistent with denervation atrophy. ${ }^{37}$ Conceivably, it is the property of tonic firing of these motor neurons (located in Onuf's nucleus in the case of the urethral and anal sphincters, and in the nucleus ambiguus in the case of the larynx) that distinguishes them from the neurons of other skeletal muscles.

In each of our patients with progressive autonomic failure and multiple system atrophy the proximal urethra was observed to be incompetent during all stages of filling. While it is generally accepted that an open bladder neck may be a sign of neurogenic bladder dysfunction, there is controversy concerning the mechanism by which proximal urethral competence is normally maintained. Some authors ${ }^{38}{ }^{39}$ have argued that sympathetic pathways are important, by contrast Nordling ${ }^{4041}$ maintains that parasympathetic efferent activity is critical. Unfortunately, since patients with progressive autonomic failure and multiple system atrophy suffer a mixed deficit of sympathetic and parasympathetic innervation of the bladder, study of these cases is unlikely to contribute to the resolution of this important question.

In the early stages of the disease, before other neurological manifestations have become apparent, the urinary frequency and reduced stream, in combination with a large residual urinary volume, may be misleading and suggest a diagnosis of outflow obstruction. However, in two of our cases and in 10 cases reported in the literature, ${ }^{842-46}$ bladder neck or prostatic resection did not result in any improvement. On the contrary, it often made the symptoms 
worse. Such results may be anticipated where surgery reduces an already compromised urethral resistance, and leaves the patient dependent upon a distal urethral sphincter which is demonstrably neuropathic.

Unfortunately, contrary to a previous report, ${ }^{8}$ we have not so far found anticholinergic drugs, which should reduce involuntary bladder contractions, to be of any value. Nor are parasympathomimetic agents useful in restoring the micturition reflex in these patients. Adrenergic agonists, such as ephedrine, might increase urethral closure pressure, but carry a risk of hypertension, due to the well-known supersensitivity to adrenergic agonists in this condition. Alpha-blocking agents, such as prazosin, theoretically should facilitate urethral relaxation during voiding attempts, but they seem to exacerbate existing orthostatic hypotension. Evidently more refined pharmacological trials are needed, since the only other prospects for these patients are the insertion of an artificial sphincter, or the recourse to either external urinary appliance in males or intermittent or indwelling catheterisation in females.

We thank Sally-Anne Gilpin for assistance with the processing and the quantitative analyses of bladder muscle biopsies and Ann Yeoman for her secretarial help.

\section{References}

${ }^{1}$ Bradbury A, Eggleston C. Postural hypotension. A report of three cases. Am Heart J 1925;1:73-86.

${ }^{2}$ Shy GM, Drager GA. A neurological syndrome associated with orthostatic hypotension. Arch Neurol 1980;2: 511-27.

${ }^{3}$ Bannister R (Ed). Autonomic Failure. A Textbook of Clinical Disorders of the Autonomic Nervous System. Oxford: Oxford University Press, 1983.

${ }^{4}$ Oppenheimer D. Autonomic Failure. A Textbook of Clinical Disorders of the Autonomic Nervous System. Bannister R, ed. Oxford: Oxford University Press, 1983:267-83.

${ }^{5}$ Onufrowicz B. On the arrangement and function of the cell groups of the sacral region of the spinal cord in man. Arch Neurol Psychopathology 1900;3:387-412.

${ }^{6}$ Bates CP, Whiteside CG, Turner-Warwick RT. Synchronous cine/pressure/flow cysto-urethrography with special reference to stress and urge incontinence. $\mathrm{Br} J$ Urol 1970;42:714-23.

${ }^{7}$ Lockhart JL, Webster GD, Sherematas W, Camuzzi FA, Carrion HC. Neurogenic bladder dysfunction in the Shy-Drager Syndrome. J Urol 1981;126:119-21.

${ }^{8}$ Wulfsohn MA. Rubenstein A. The management of ShyDrager syndrome with propantheline and intermittent self-catheterisation. A case report. J Urol 1981; 126:122-3.

${ }^{9}$ Fowler CJ, Kirby RS, Harrison MJG, Milroy EJG, Turner-Warwick RT. Individual motor unit analysis in the diagnosis of disorders of urethral sphincter innervation. J Neurol Neurosurg Psychiatry 1984;47: 637-41.

${ }^{10}$ Gomori G. Microscopic Histochemistry: Principles and Practise. Chicago: University of Chicago, 1952:208-14.

${ }^{11}$ Spriggs TLB, Lever JD, Rees PM, Graham JDP. Controlled formaldehyde catecholamine condensation in cryostat sections to show adrenergic nerves by fluorescence. Stain Technology 1966;41:323-7.

${ }^{12}$ Langworthy OR, Kolb LC. The encephalic control of tone in the musculature of the urinary bladder. Brain 1933;56:371-82.

${ }^{13}$ Lewin RJ, Porter RW. Inhibition of spontaneous bladder activity by stimulation of the globus pallidus. Neurology (Minneap) 1965;15:1049-52.

${ }^{14}$ Lewin RJ, Dillard GV, Porter RW. Extrapyramidal inhibition of the urinary bladder. Brain Res 1967;4:301-7.

${ }^{15}$ Anderson JT, Bradley WE. Cystometric sphincter and electromyelographic abnormalities in Parkinson's disease. J Urol 1976;116:75-8.

${ }^{16}$ Andersen JT, Hebjorn S, Frimodt-Moller C, Walter S, Worm-Petersen J. Disturbances of micturition in Parkinson's disease. Acta Neurol Scand 1976;53:161-70.

${ }^{17}$ Denny-Brown DE, Robertson EG. On the physiology of micturition. Brain 1933;56:149-90.

${ }^{18}$ Sung JH, Mastri AR, Segal E. Pathology of the ShyDrager Syndrome. J Neuropathol Exp Neurol 1978;38:253-68.

${ }^{19}$ Morgan C, Nadelhaft I, De Groat WC. Location of bladder preganglionic neurones within the sacral parasympathetic nucleus of the cat. Neurosc Lett 1979; 14:189-94.

${ }^{20}$ Barrington FJF. The effect of lesions of the hind and midbrain on micturition in the cat. $Q J$ Exp Physiol 1925;15:81-102.

${ }^{21}$ Bradley WE, Conway CJ. Bladder representation in the pontine-mesencephalic reticular formation. Exp Neurol 1966;16:237-49.

${ }^{22}$ Tokunaga S, Kuru M. Vesico-constricter centre and vesico-relaxer centre in the medulla. Jpn $J$ Physiol 1959;9:363-74.

${ }^{23}$ De Groat WC. Nervous control of the urinary bladder of the cat. Brain Res 1975;87:201-11.

${ }^{24}$ Zeigler MD, Lake CR, Kopin IJ. The sympathetic nervous system defect in primary orthostatic hypotension. $N$ Engl J Med 1977;296:293-7.

${ }^{25}$ Bannister R, Sever P, Gross M. Cardiovascular reflexes and biochemical responses in progressive autonomic failure. Brain 1977;100:327-44.

${ }^{26}$ Nanda RN, Boyle FC, Gillespie JS, Johnson RH, Keogh HJ. Idiopathic orthostatic hypotension from failure of noradrenaline release in a patient with vasomotor innervation. J Neurol Neurosurg Psychiatry 1977; 40:11-9.

${ }^{27}$ Bannister R, Crowe R, Eames R, Burnstock G. Adrenergic innervation in autonomic failure. Neurology (NY) 1981;31:1501-6.

${ }^{28}$ Gosling JA, Dixon JS, Lendon RG. The autonomic innervation of the human male and female bladder neck and urethra. J Urol 1977;118:302-5.

${ }^{29}$ Sakuta MS, Nakanishi T, Toyakura Y. Anal muscle elec- 
tromyograms differ in lateral sclerosis and Shy-Drager Syndrome. Neurology (Minneap) 1978;28:1289-93.

${ }^{30}$ Sung JH, Mastri AR. Spinal autonomic neurones in Werdnig-Hoffman disease, mannosidosis and Hurlers syndrome: distribution of autonomic neurones in the sacral spinal cord. $J$ Neuropathol Exp Neurol 1980;39:441-5.

${ }^{31}$ Kuzuhara S, Kanazawa I, Nakanishi T. Topographical localisation of the Onuf's nuclear neurones innervating the rectal and vesical striated sphincter muscles: A retrograde fluorescent double labelling in cat and dog. Neurosci Lett 1980;16:125-30.

${ }^{32}$ Swash M. Vulnerability of lower brachial myotomes in motor neurone disease: a clinical and single fibre EMG study. J Neurol Sci 1980;47:59-68.

${ }^{33}$ Galassi G, Nemni R, Bavaldi A, Gibertoni M, Colombo A. Peripheral neuropthy in multiple system atrophy with autonomic failure. Neurology (NY) 1982;32: 1116-21.

${ }^{34}$ Mannen T, Iwata M, Toyakura Y, Nagashima K. Preservation of a certain motor neurone group in the sacral cord in amyotrophic lateral sclerosis: its clinical significance. J Neurol Neurosurg Psychiatry 1977; 40:464-9.

${ }^{35}$ Iwata M, Hirano A. Sparing of the Onufrowicz nucleus in sacral anterior horns. Ann Neurol 1978;4:245-9.

${ }^{36}$ Guindi GM, Bannister R, Gibson WPR, Payne JH. Laryngeal electromyography in multiple system atrophy with autonomic failure. $J$ Neurol Neurosurg Psychiatry 1981;44:49-53.

${ }^{37}$ Bannister R, Gibson M, Michaels L, Oppenheimer D.
Laryngeal abductor paralysis in multiple system atrophy. Brain 1981;104:351-86.

${ }^{38}$ Barbalias GA, Blaivas JG. Neurological implications of the pathologically open bladder neck. J Urol 1983; 129:780-2.

${ }^{39}$ Woodside JR, McGuire EJ. Urethral hypotonicity after suprasacral spinal cord injury. $J$ Urol 1979;121:783-5.

${ }^{40}$ Nordling J, Meyhoff HH, Oleson KP. Cystourethrographic appearance of the bladder and posterior urethra in neuromuscular disorders of the lower urinary tract. Scand J Urol Nephrol 1982;16:115-24.

${ }^{41}$ Nordling J. Influence of the sympathetic nervous system on lower urinary tract in man. Neurology and Urodynamics 1983;2:3-26.

${ }^{42}$ Chokroverty S, Barron KD, Katz FH, Greco FD, Shang JT. The syndrome of primary orthostatic hypotension. Brain 1969;92:743-68.

${ }^{43}$ Hughes RC, Cartidge NEF, Millac P. Primary neurogenic orthostatic hypotension. J Neurol Neurosurg Psychiatry 1970;33:363-71.

${ }^{44}$ Bannister R, Oppenheimer DR. Degenerative diseases of the nervous system associated with autonomic failure. Brain 1972;95:457-74.

${ }^{45}$ Khurana RK, Nelson E, Azzarelli B, Garcia JH. Shy-Drager Syndrome: Diagnosis and treatment of cholinergic dysfunction. Neurology (Minneap) 1980;30: 805-9.

${ }^{46}$ Johnson RH, Lee GJ, Oppenheimer DR, Spalding JMK. Autonomic failure with orthostatic hypotension due to intermediolateral column degeneration. $Q J$ Med 1966; 35:276-92. 